\title{
Diet/Body Weight, Eating Disorders
}

\author{
Satya SS Narina* \\ Department of Horticulture, Agricultural College, Bapatla, India \\ *Corresponding Author: Satya SS Narina, Department of Horticulture, Agricultural \\ College, Bapatla, India.
}

DOI: $10.31080 /$ ASNH.2020.04.0626

Diet is the amount of food material we accept to take on daily basis after thorough analysis of its quality. Body weight is the amount or mass of tissue gained after taking in food material by a human being over a period of time. Eating disorders are the irregularities observed on daily basis, might be due to no, low or high food intakes, leading to major human health risks such as diabetes, and obesity. These irregular food habits in quantity might also cause heart attacks, hyper or hypo thyroidism, low or high blood pressure due to disturbances in the regular blood glucose and electrolyte levels or due to reduced essential amino acids required for normal human metabolism. Usually these eating disorders are observed in actors, sports personnel or specific ballet or gymnasts besides business men and professionals with tight work and family life schedules.

Some people like to maintain their body weight for beauty, or personal outlook and start exercising severely to exhaust (purge) the food taken in on every day so as to have low body weight and maintain physical outlook. Some people will do forced vomiting to purge out the food taken in out of guilt. Low food intakes result in low food absorption in the long run causing severe mental depression or loss of concentration in doing regular simple daily tasks due to reduced energy levels. The low food intake causes disorders with low body mass index (BMI) like Anorexia nervosa that might sometimes result in miscarriages in pregnant women besides infertility, thyroidism, delayed menarche, and rarely we see joint swelling or osteoporosis due to severe stress caused due to physical exercises.

Due to favouritism towards tasty, crunchy and starchy foods, some people does not want to leave consumption of certain foods with richness in carbohydrates, sugars and fat/oil. Sometimes, people will eat more out of their depression levels. These people display symptoms of quick eating habit, eating alone and even without any hunger in large amounts that might lead eventually to cardio vascular diseases and diabetes. The depression might sometimes lead to various levels of addiction to the dangerous liquid diets including tea, coffee, alcohol, narcotics or any locally available cheap liquor products with no nutritive or health value. Improper food intake in high quantities without quality lead to high BMI causing disorders like Bulimia nervosa, or Binge eating disorder. These disorders result in psychologic distress, type II diabetes, hyper tension, arthritis, sleep apnoea, dyslipidaemia and gall stones.

Lets discuss about the right foods of choice to keep the body weight under control. Always balanced diet is the solution to the body weight problems. Developing daily habits of consuming a full plate containing 1) Fresh fruits that supply natural fructose and easily digestible simple sugars. These provide instant energy unlike the complex food materials that require time in breaking them down to glucose to provide required energy. As well storing these complex macronutrients require more space in the human body system in forming various types of adepose tissues filled with fat and lipid reserves, 2) Replacing animal fibre with alternative high energy low fibre foods of plant origin for easy bowl movement and metabolism. For example incorporating fresh leafy vegetables not only rich in iron and zinc minerals as well purify blood. The choice of vegetarian diet also help to reduce the calorific load and high BMI resulted due to animal meat intake. 3) Avoiding or limiting the consumption of beverages of no value in nutrition or metabolism on daily basis. Because these beverages not only increase body sugar intake leading to disturbance in BMI, but also affect normal human functions. 4) Eating nuts and salads at least once in a week in place of staple foods of regular diet to compensate any loss in energy levels due to low calorie intakes of vegetarian and to balance the dietary values.

In our present modern society, what are the right choices of work habits to control irregularities in food intake?. Always better choosing a normal work schedules of eight hours as the family is always a priority compared to work, though occupation supports our livelihood and professional career. Sometimes, irregularities in food intake develop slowly without our notice due to dedication or seriousness of our never ending work targets or tasks to be handled in each and every individual's profession. Therefore, limiting the tasks per day is highly dependant on the benefits out of those at the cost of family like money or recognition?. Nevertheless, again squeezing a second to take care of the body that supports all these activities is invaluable. Realization by keeping a timer to stop individual from scheduled task at home or work to remind their sched- 
uled intake of valuable food that is necessary for body functioning is critical in solving lot of health problems and to save life.

Awareness about human diet restrictions was there since 1900 's worldwide through research and demonstration by the federal departments of food and nutrition, but practical adoptability by every human is purely personal understanding of the concept and individual choice. By treating humans with diet restrictions and psychotherapy might help to control eating disorders or obesity. There are stimulants and pancreatic lipase inhibitors (orlistat) that maintain metabolic absorption of food avoiding fat or harmful food substances. In modern societies of nuclear families in isolated communities, eating with a family of friends at work is also not commonly seen due to difference in schedules of every working human. Similarly at home, eating with their family members is also invisible. Family meeting at dining table always keep up with our food quality besides with healthy smiles we share with our family.

The addiction towards bad foods or food eating habits not only spoil individual's health, but also cause disturbances in their close human society or relationships that were tightly linked with love, care and humanity. Therefore, persons who cares for themselves by controlling their bad food intakes or food habits of irregularity is not a big hassle. Because by complete avoidance or setting limits, indicate a growth in humanity and definite dependable care shown for their loving families. Last but not least, "watching our plate carefully to exclude avoidable food before consuming the valuable contents with benefits in it" is always vital step to keep up with individuals nutritional requirements for balanced and healthy nutrition. Because these are not those good olden days of 1800s, where thrash in might balance with the inborn immunity acquired from both previous generations and food they ate as a standard choice.

\section{Assets from publication with us}

- Prompt Acknowledgement after receiving the article

- Thorough Double blinded peer review

- Rapid Publication

- Issue of Publication Certificate

- High visibility of your Published work

Website: www.actascientific.com/

Submit Article: www.actascientific.com/submission.php

Email us: editor@actascientific.com

Contact us: +919182824667 